\title{
Parenteral Insecticide Injection for Suicidal Attempt: A Case Report
}

\author{
Ali Kemal Erenler1, Gökhan Başara', Abdülcelil Kayabaş² \\ ${ }^{1}$ Department of Emergency Medicine, Samsun Education and Research Hospital, Samsun, Turkey \\ ${ }^{2}$ Department of Internal Medicine, Samsun Education and Research Hospital, Samsun, Turkey \\ Email: akerenler@hotmail.com
}

Received 3 June 2014; revised 19 July 2014; accepted 1 August 2014

Copyright (C) 2014 by authors and Scientific Research Publishing Inc.

This work is licensed under the Creative Commons Attribution International License (CC BY). http://creativecommons.org/licenses/by/4.0/

(c) (i) Open Access

\begin{abstract}
Poisoning by insecticides is a public health problem, particularly in developing countries. Insecticide poisoning may occur due to ingestion, inhalation or skin contact and is commonly associated with psychiatric illnesses. However, intramuscular injection of these chemicals is rare in the literature. In this report, we represent you a case of 35-year-old female who presented to our Emergency Department due to parenteral insecticide injection after an argument with her husband. A tender swelling was observed on the upper region of left upper extremity, underneath the shoulder. The patient did not develop any signs and symptoms of organophosphate poisoning and, after follow-up, the patient was discharged with total recovery. Even in the absence of systemic effects of OP, clinicians must be aware of possible complications of intramuscular injection of OPs such as cellulitis and abscess. We aimed to raise the awareness to this rare condition.
\end{abstract}

\section{Keywords}

Organophosphate Poisoning, Parenteral Injection, Emergency Department

\section{Introduction}

Suicide is defined as the conscious act of self induced annihilation and is among the three leading causes of death among those middle aged people in several countries which is complex with psychological, social, biological, cultural and environmental factors involved [1]. Pesticide self-poisoning causes hundreds of thousands of deaths each year in rural parts of the developing world [2] [3]. In developing countries, household insecticides are easily obtained, contributing to the occurrence of suicide. Household insecticides are classified as chlorinated hydrocarbons, acetyl cholinesterase inhibitors and botanical agents. Acetyl cholinesterase inhibitors include carbamates and organophosphates [4]. Poisoning by insecticides via ingestion, inhalation or dermal con- 
tact is common. However, suicide via the parenteral route has rarely been reported. In this report, we represent you a middle-aged female patient committed suicide by parenteral insecticide injection.

\section{Case}

A 35-year-old female presented to our Emergency Department (ED) due to swelling and pain on lower region of her left shoulder. On anamnesis, it was understood that the patient has injected a household insecticide (by taking the aerosole into the injector) for suicidal attempt after an argument with her husband 12 hours ago. After an interview with her relatives, it was understood that the chemical used for suicide was dichlorvos, an organophosphorus (OP) compound widely used to control household pests. On admission, her vital signs were as follows; blood pressure: $130 / 80 \mathrm{mmHg}(90 / 60 \mathrm{~mm} / \mathrm{Hg}$ to $120 / 80 \mathrm{~mm} / \mathrm{Hg})$, pulse: $80 /$ minute (60 - 100/min), respiratory rate: $20 /$ minute $(12-20 / \mathrm{min})$, temperature: $36.5^{\circ} \mathrm{C}\left(36.5^{\circ} \mathrm{C}-37.5^{\circ} \mathrm{C}\right)$. The patient was alert, well oriented and cooperative. Her respiratory and heart sounds were normal. On physical examination, there was a $5 \times 5 \mathrm{~cm}$ swelling and erythema on upper region of left upper extremity under her shoulder (Figure 1). The lesion was sensitive and warm on palpation.

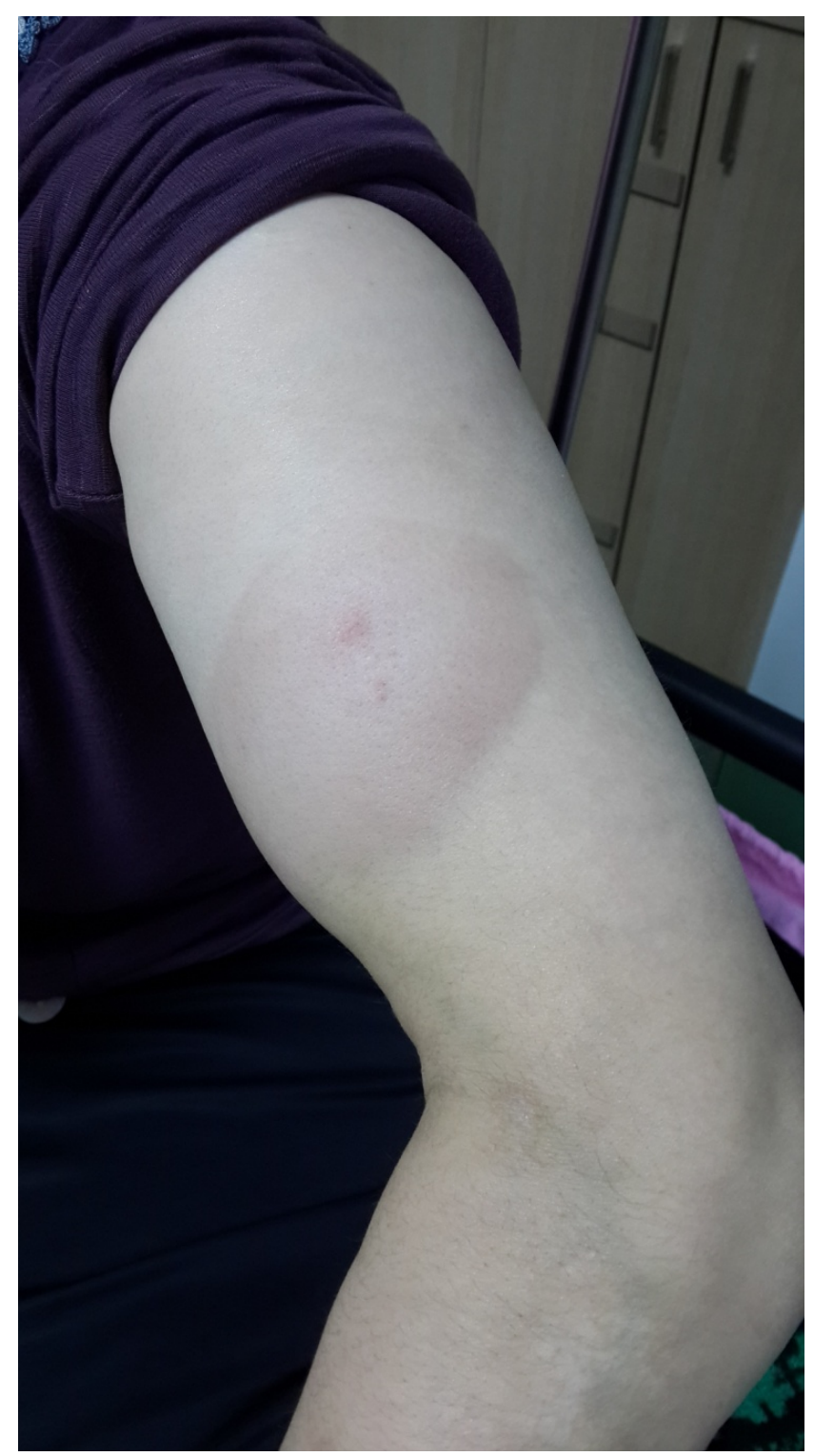

Figure 1. Injection site of the organophosphate compound. 
A complete blood count and biochemical analysis, including pseudocholinesterase, were performed and determined to be normal (pseudocholinesterse: $8453 \mathrm{U} / \mathrm{L}$, reference: 4900 - 11,900 U/L). A humerus X-ray was performed in order to exclude presence of a possible foreign body or subcutaneous air and was found to be normal. An IV infusion of crystalloid solution was administered. The extremity was elevated. Atropine or pralidoxime were not administered because there were not signs of cholinergic syndrome due to a possible OP poisoning. The patient was consultated with a internal medicine specialist and hospitalized for observation. During the 3-day follow-up, pseudocholinesterase level did not reduce, any physical examination abnormalities were not determined and, after psychiatry consultation, the patient was discharged from the hospital. After 7 days, patient was called for control. Blood tests, including pseudocholinesterase level were obtained. Examination of the limb was normal, swelling has regressed and local tenderness has disappeared. Blood test results were normal and the patient was accepted to be totally recovered. Informed consent was obtained from the patient.

\section{Discussion}

Pesticide self-poisoning causes one third of global suicides. Current strategies to prevent deaths from pesticide poisoning include better access and quality of medical management, improved mental health care, safer use and storage in communities, and restriction of availability of highly toxic pesticides [5]. In Turkey, however, such toxic chemicals are still easily available and, thus, poisoning related to such product is still a public health problem. Organophosphate poisoning occurs mainly via the gastrointestinal and respiratory tracts and the skin. Exposure to the chemical via other routes causes varying symptoms [6]. In our case, the patient chose a very rare route. She has injected the insecticide via an injector into her arm.

In a study, Goldberg et al. [7] reported two patients admitted to ED due to suicidal attempt by injecting themselves with commercially available household spray insecticides presented with cellulitis at and adjacent to the injection sites, and both were admitted for intravenous antibiotics, warm soaks, and elevation. In both patients abscesses subsequently developed in the areas of cellulitis.

Sundarka et al. has reported an 18-year-old woman patient who injected herself OP insecticide. She came to the hospital, 3 hours after the injection to the rear side of her left hand, suffering from the pain. No pathologies were found during her physical examination; but during the local examination of the injection region, thrombosis cellulitis symptoms were found in the distal region of her arm [8]. Our patient had similarities with this case. However, in our case, even 12 hours has passed, we could not determine any signs of cellulitis or abscess.

Symptoms and signs of OP poisoning vary. Bradycardia, tachycardia, hypotension, hypertension, rhinorrhoea, bronchorrhoea, bronchospasm, increased salivation, diarrhea, urinary continence, miosis, blurred vision, increased lacrimation, weakness, fasciculations, cramps, paralysis, ataxia, convulsions, tremors, coma, respiratory depression and circulatory collapse may be seen [9]. Our patient did not have severe cholinergic toxicity from the OP exposure, and she did not develop infectious complications on the site of infection. This may be associated with the scarcity of the chemical injected. Presumably, the amount of the chemical injected was not of sufficient amount to pass through the circulatory system and cause the systemic effects of OP poisoning.

In cases of parenteral injection of OPs, attention must be paid to the possibility of late onset of the clinical manifestations of the poisoning, and to the fact that usual measures to reduce exposure to the OP, such as induction of vomiting, gastric lavage and use of activated charcoal are probably ineffective. Local complications at the site of the injection, like necrosis and abscesses are also expected findings [10].

In treatment of poisoning by OP insecticides, atropine is used. An initial dose of $1.2 \mathrm{mg}$ should be doubled every 5 minutes, as atropine takes only a few minutes to work. Reassessment of the patient every 5 - 10 minutes is necessary in order to determine the level at which the patient's secretions have been controlled and respiratory distress has abated. In addition to atropine, the cholinesterase regenerating agent pralidoxime (initial and maintenance doses) is recommended to reverse nicotinic signs of OP poisoning (especially fasciculations and respiratory muscle weakness), but pralidoxime must be initiated before the cholinesterase enzyme has irreversibly bound to the organophosphate agent. This process is known as "aging" of the enzyme and pralidoxime is not useful after aging occurs. The use of pralidoxime has been increasingly controversial due to the relatively new data calling its efficacy into question and more research is needed to identify which patients will most benefit from this antidote. Lastly, the use of benzodiazepines is warranted to combat seizures (due to Central nervous system cholinergic excess) and control atropine-related agitation [9]. In our case, pseudocholinesterase level did not decrease, so we initiated supportive therapy instead of antidotal therapy. 


\section{Conclusion}

Organophosphorus poisoning is a common public health problem in developing countries where agriculture is a common profession. The usual routes of poisoning are oral, inhalation or skin contact. It may occur both unintentional and intentional [9]. When a patient is admitted to the ED due to localized swelling and tenderness, clinicians must remember possible OP injection even though any clinical signs and symptoms do not exist.

\section{References}

[1] WHO (2011) Suicide Prevention (SUPRE). World Health Organization, Geneva.

[2] Eddleston, M. and Phillips, M.R. (2004) Self Poisoning with Pesticides. BMJ, 328, 42-44. http://dx.doi.org/10.1136/bmj.328.7430.42

[3] Gunnell, D. and Eddleston, M. (2003) Suicide by Intentional Ingestion of Pesticides: A Continuing Tragedy in Developing Countries. International Journal of Epidemiology, 32, 902-909. http://dx.doi.org/10.1093/ije/dyg307

[4] Buchman, M.T. (2000) Upper Extremity İnjection of Household Insecticide: A Report of Five Cases. Journal of Hand Surgery (American Volume), 25, 764-767. http://dx.doi.org/10.1053/jhsu.2000.8643

[5] Eddleston, M., Adhikari, S., Egodage, S., Ranganath, H., Mohamed, F., Manuweera, G., Azher, S., Jayamanne, S., Juzczak, E., Sheriff, M.R., Dawson, A.H. and Buckley, N.A. (2012) Effects of a Provincial Ban of Two Toxic Organophosphorus İnsecticides on Pesticide Poisoning Hospital Admissions. Clinical Toxicology, 50, 202-209. http://dx.doi.org/10.3109/15563650.2012.660573

[6] Liu, H., Kan, B., Jian, X., Zhang, W., Zhou, Q. and Wang, J. (2013) Parasuicidal Poisoning by Intramuscular Injection of Insecticide: A Case Report. Experimental and Therapeutic Medicine, 6, 696-698.

[7] Goldberg, L.H., Shupp, D., Weitz, H.H. and Zeccardi, J.A. (1982) Injection of Household Spray Insecticide. Annals of Emergency Medicine, 11, 626-629. http://dx.doi.org/10.1016/S0196-0644(82)80207-2

[8] Sundarka, M.K., Gupta, H.L., Parakh, N., et al. (2000) Self Injection of Insecticide. The Journal of the Association of Physicians of India, 48, 856.

[9] Malla, G., Basnet, B., Vohra, R., Lohani, S.P., Yadav, A. and Dhungana, V. (2013) Parenteral Organophosphorus Poisoning in a Rural Emergency Department: A Case Report. BMC Research Notes, 6, 524. http://dx.doi.org/10.1186/1756-0500-6-524

[10] de Andrade Nishioka, S. (1994) Parenteral Injection of Organophosphate Insecticide. Apropos of Two Cases. Sao Paulo Medical Journal, 112, 561-563. http://dx.doi.org/10.1590/S1516-31801994000200008 
Scientific Research Publishing (SCIRP) is one of the largest Open Access journal publishers. It is currently publishing more than 200 open access, online, peer-reviewed journals covering a wide range of academic disciplines. SCIRP serves the worldwide academic communities and contributes to the progress and application of science with its publication.

Other selected journals from SCIRP are listed as below. Submit your manuscript to us via either submit@scirp.org or Online Submission Portal.
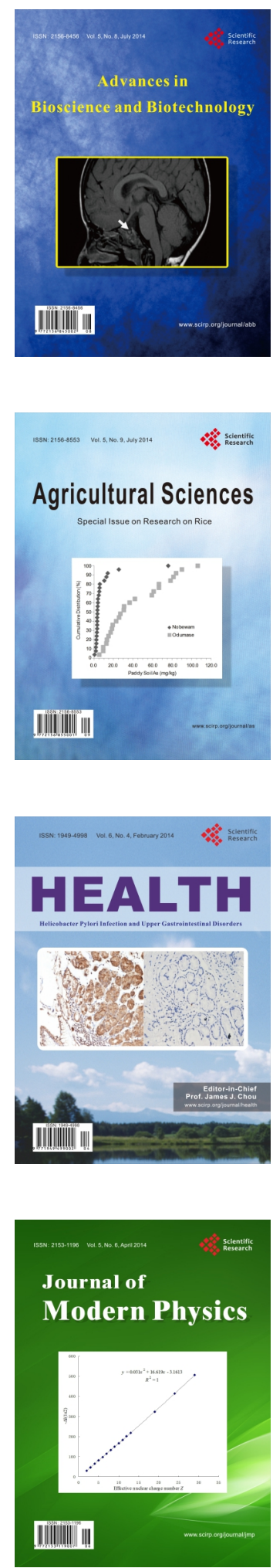
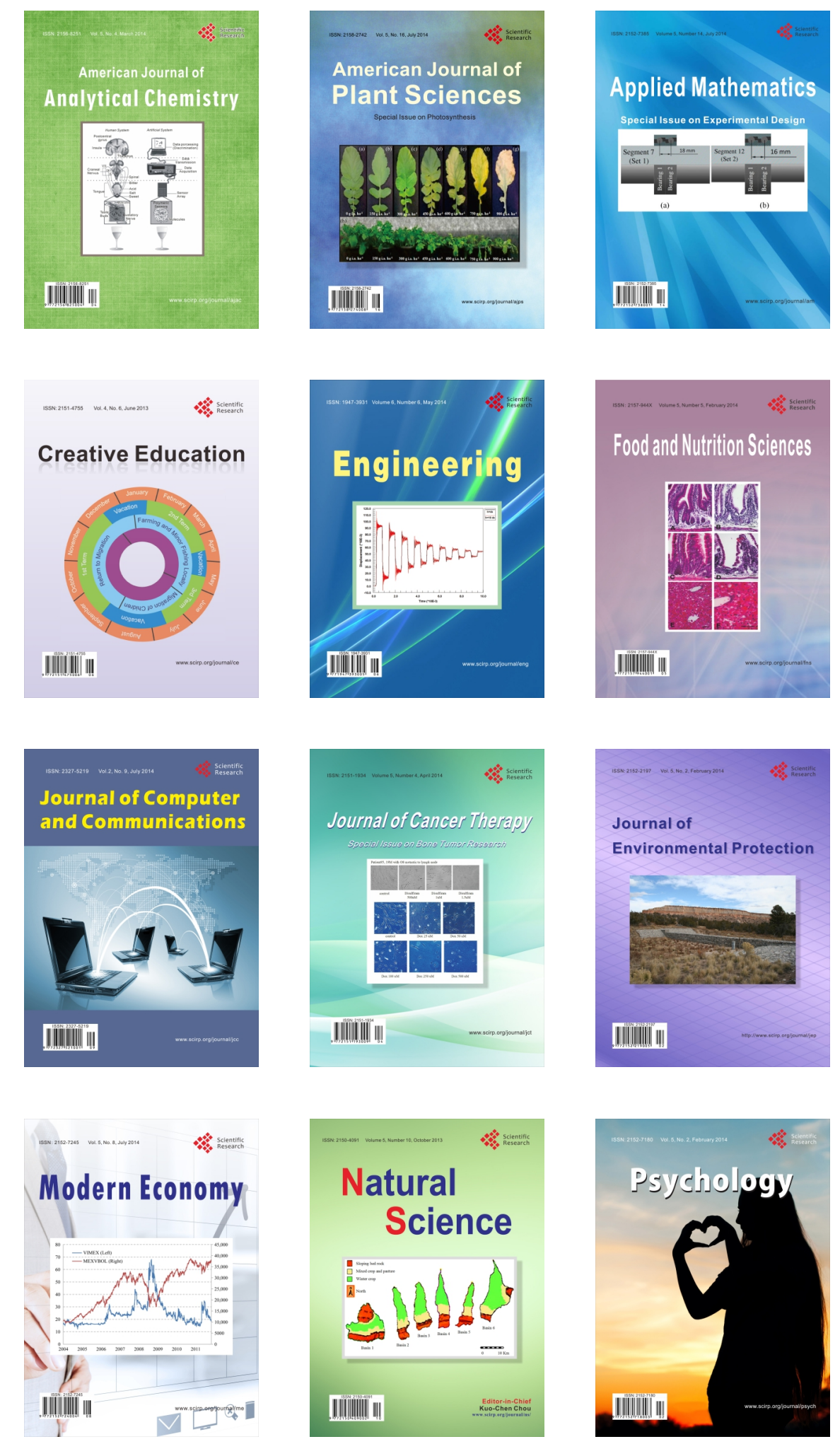